\title{
Decision Making Regarding Key Elements of Korean Disaster Psychiatric Assistance Teams Using the Analytic Hierarchy Process
}

\author{
Sun-Jin Jo', Kyoung-Sae $\mathrm{Na}^{2}$, Joo Eon Park ${ }^{3}$, and Myung-Soo Lee ${ }^{4 凶}$ \\ 1'Department of Preventive Medicine, College of Medicine, The Catholic University of Korea, Seoul, Republic of Korea \\ 2Department of Psychiatry, Gachon University Gil Medical Center, Incheon, Republic of Korea \\ ${ }^{3}$ Department of Psychiatry, Keyo Hospital, Uiwang, Republic of Korea \\ ${ }^{4}$ Deptartment of Psychiatry, Yong-in Mental Hospital, Yongin, Republic of Korea
}

\begin{abstract}
Objective The purpose of this study was to determine the key components of Korean disaster psychiatric assistant teams (K-DPATs), to set up new mental health service providing system for the disaster victims.

Methods We conducted an analytic hierarchy process (AHP) involving disaster mental health experts, using a pairwise comparison questionnaire to compare the relative importance of the key components of the Korean disaster mental health response system. In total, 41 experts completed the first online survey; of these, 36 completed the second survey. Ten experts participated in panel meetings and discussed the results of the survey and AHP process.

Results It was agreed that K-DPATs should be independent of the existing mental health system (70.1\%), funding for K-DPATs should be provided by the Ministry of Public Safety, and the system should be managed by the Ministry of Health (65.8\%). Experts shared the view that K-DPAT leaders would be suitable key decision makers for all types of disaster, with the exception of those involving infectious diseases.
\end{abstract}

Conclusion K-DPAT, a new model for disaster mental health response systems could improve the insufficiency of the current system, address problems such as fragmentation, and fulfill disaster victims' unmet need for early professional intervention.

Psychiatry Investig 2018;15(7):663-669

Key Words Disaster, Mental health services, Disaster psychiatric assistant teams, Decision making, Analytic hierarchy process.

\section{INTRODUCTION}

Disasters frequently cause psychological pain, and failure to implement appropriate interventions in a timely manner could aggravate socioeconomic burden. ${ }^{1}$ The following key features must be considered in establishing an effective disaster response system. First, although disasters generally occur without warning, and response measures are implemented over a short period (e.g., a few weeks), recovery and restoration last from several months to a number of years. ${ }^{2}$ Second,

Received: October 9, 2017 Revised: December 26, 2017

Accepted: January 13, 2018

$\triangle$ Correspondence: Myung-Soo Lee, MD, MPH

Deptartment of Psychiatry, Yongin Mental Hospital, 940 Jungbu-daero, Giheung-gu, Yongin 17089, Republic of Korea

Tel: +82-31-288-0202, Fax: +82-31-288-0107, E-mail: mslee1010@gmail.com

(c) This is an Open Access article distributed under the terms of the Creative Commons Attribution Non-Commercial License (https://creativecommons.org/licenses/bync/4.0) which permits unrestricted non-commercial use, distribution, and reproduction in any medium, provided the original work is properly cited. various personal and social factors play a role during disasters, leading to multilevel psychosocial repercussions. ${ }^{3}$ Each country and region displays idiosyncratic socio-cultural features and is vulnerable to certain types of disaster. From a humanitarian perspective, the provision of psychosocial support and services during specific phases of disasters could be based on well-established guidelines. ${ }^{4,5}$ However, issues pertaining to the decision as to which organization should be responsible for controlling and managing human resources and services and how the private sector and government institutions should coordinate and arrange expert contributions depends almost entirely on the country's infrastructure and the type of disaster involved.

Most disaster mental health response systems were developed in North America, ${ }^{6}$ Europe, ${ }^{7}$ and Japan. ${ }^{8}$ These countries have established optimal disaster mental health response systems based on their unique sociopolitical and healthcare infrastructures. In the United Kingdom, autonomous local 
systems and a healthcare system centered around the National Health Service (NHS) have allowed NHS trusts in each region to lead proactive planning and personnel training related to postdisaster mental health services, interagency collaboration, and delivery of professional mental health services following a disaster. ${ }^{9}$ Many Asian countries have established response systems tailored to their own major disasters. For instance, since Typhoon Morakot struck Taiwan in August 2009, Taiwan has established a disaster mental health response system that facilitates cooperation between the private sector, nonprofit organizations, and the public sector. ${ }^{10}$ In addition, Thailand ${ }^{11}$ and the Philippines have established disaster mental health response systems that are applicable to their respective environments.

Japan has established a disaster response system tailored to its unique situation, in which regional disaster relief and recovery efforts are seriously undermined by severe earthquakes and tsunamis. ${ }^{12-14}$ For example, Japan instituted a comprehensive information system managed by the National Information Center for Disaster Mental Health and formed Disaster Psychiatric Assistant Teams (DPATs) to be dispatched to affected areas from nearby regions or all over the nation when an earthquake or tsunami strikes. The Japanese government also installed centers that provide comprehensive services, such as psychosocial counseling and education, in severely affected regions such as Fukushima, where a nuclear plant exploded following a tsunami in 2011. Japanese DPATs play a role in immediate support and coordination for affected people with disaster. Japanese DPAT is multi-disciplinary team and currently 38 trained teams are set up. They provide crisis intervention services for the psychiatric patients of disaster areas and emotional problems of general population. One important thing is governance. Japanese DPAT is primarily based on mental hospital but controlled and coordinated by regional government of disaster area. According to the size of disasters DPAT from other areas can be dispatched by the request of regional headquarter of disaster area and decision of National Information Center for Disaster Mental Health. DPAT also work with professional volunteers from private sector and all these activities are coordinated by regional government.

Korea is less severely affected by earthquakes or typhoons relative to neighboring East Asian countries, such as China and Japan, but it has been vulnerable to casualties and the social repercussions of manmade disasters. For example, the Sewol ferry disaster, which occurred on April 16, 2014, involved a tragic incident in which 304 out of 476 passengers on the ferry drowned. ${ }^{15,16}$ Following the 2014 Sewol ferry incident, an amendment to the law assigned responsibility for the control of disaster responses to the Ministry of Public
Safety and Security (MPSS). South Korea is divided into 17 regional autonomies and 226 local autonomies. The MPSS funds and supports 17 psychological support centers for disasters nationwide with the collaboration of Korean Red Cross. The National Mental Health Center has established the Disaster and Crisis Psychology Assistance Team, which is affiliated with the Ministry of Health and Welfare (MOHW), and there are currently 17 regional and 209 local mental health centers in operation, providing various mental health services for the general population and individuals with mental illnesses. ${ }^{17}$ In terms of delivering mental health services to disaster victims, the functions of the MPSS and MOHW service systems overlap in some regions and are coordinated in others. The increasing demand for mental health services for disaster victims has necessitated a mental health service tailored to Korea's idiosyncratic features and situations. The important resources for disaster mental health services are mental health professionals who are working in community mental health field and in private sectors. Even though each governance that is of MPSS and MOHW has its own mobilizing systems, the operating systems for those human resources are not clear.

It is both difficult and inappropriate to implement postdisaster mental health service models developed in other countries, in the contexts of their unique environments. ${ }^{18,19}$ The present study aimed to determine the key components of Korean version of disaster psychiatric assistant teams (K-DPATs), to contribute to the reformation of the Korean disaster mental health response system.

\section{METHODS}

\section{Analytic Hierarchy Process}

The analytic hierarchy process (AHP) was used to develop policy priorities for the establishment of K-DPAT structures for disasters in general. ${ }^{20}$ The AHP is a theory of measurement for decision-making that have experts to judge how much more one element dominates another through pairwise comparisons, and has been adopted in various decision-making research. $^{21}$

The AHP technique is a popular method for analyzing decision-making alternatives using multiple qualitative criteria. One of the strengths of this technique is that it allows comparison of all mutually comparable components in structuring the content of a specific domain and measures and reflects the consistency of judgments. ${ }^{22}$

There are four steps in the analytic hierarchy process ${ }^{20}$ to generate priorities to make a decision: "1) define the problem and determine the kind of knowledge sought; 2) structure the decision hierarchy from the top with the goal of the deci- 
sion, then the objectives from a broad perspective, through the intermediate levels to the lowest level; 3) construct a set of pairwise comparison matrices; and 4) use the priorities obtained from the comparisons to weigh the priorities in the level immediately below. Do this for every element. Then for each element in the level below add its weighed values and obtain its overall or global priority. Continue this process of weighing and adding until the final priorities of the alternatives in the bottom most level are obtained."

\section{Participants and measurement}

First step to perform AHP analysis, we reviewed the literature regarding foreign, particularly Japanese, models and interviewed experts. We also collected data from staff members at regional mental health centers nationwide to develop a questionnaire. This pre-test results were used to compose the structure of the decision hierarchy of K-DPAT and the alternative terms compared with pairwise.

Eight components of the K-DPAT structure were selected for 1st survey: 1) overarching structure; 2) location of headquarter; 3) type of mobilization; 4) member qualifications; 5) certification system; 6) type of supplementary education; 7) remuneration system for participation; and 8) funding source, and the alternative terms with pairwise comparison was presented in each component. According to the suggestion of Saaty, ${ }^{20}$ likert scale of 9-point were adopted to rate relative importance for each pairwise comparison.

As the second step, the authors sent invitation emails to complete an online survey to 60 mental health professionals including psychiatrists, psychiatric nurses, psychiatric social workers, and psychologists, with disaster-related research, fieldwork, educational, or clinical experience. Of these, 41 completed the questionnaire, and their data were included in the first round of analysis (Table 1).

Thereafter, a panel discussion involving 10 experts was held as the third step. The expert group was consisted in consideration of the field of expertise and experience of disaster mental health support, which enable various opinions to be raised. They discussed whether each component of nine on the KDPAT structure was agreed or not, and suggested 2nd survey to make decision on the non-agreement component and the additional experts' opinions related with the K-DPAT. The experts agreed that it was considered to be an consensus when the difference of the relative importance between the alternatives of the highest and the next highest priorities was greater than or equal to $10 \%$ point in the first survey, which was a process to select the components to be reassessed. As a result, consensus was reached on seven components of the K-DPAT structures such as overarching structure, member qualification, certification system, types of supplementary education, remuneration systems for participants, and funding source in the first survey.

For the second survey, the questionnaire included two components in which consensus was not reached such as location of the headquarters or type of mobilization, and additional questions as to location of expert recruitment and supplement education, and on-site leaders for each of the four types of disaster (i.e., large-scale natural disaster, mass-casualty incident, small-scale incident, and infectious epidemic). Invitations to complete the second online survey were distributed to the experts who had completed the first online survey ( $n=41)$; of these, 36 responded. The final draft was reviewed and confirmed via panel discussion, based on the second survey results.

\section{Data collection and analysis}

Data were collected via email between May 2 and 27, 2016. The survey consisted of pairwise items, with the importance of each alternative rated from 1 to 9 . Relative priorities were calculated according to the AHP logic developed by Saaty ${ }^{20}$

Table 1. General characteristics ( $N=41)$

\begin{tabular}{|c|c|c|}
\hline Variables & Categories & $\mathrm{N}$ (\% or range, median) \\
\hline \multirow[t]{2}{*}{ Gender } & Male & $19(46.3)$ \\
\hline & Female & $22(53.7)$ \\
\hline \multirow[t]{4}{*}{ Fields of expertise } & Psychiatrist & $21(51.2)$ \\
\hline & Clinical psychologist & $6(14.6)$ \\
\hline & Psychiatric nurse & $8(19.5)$ \\
\hline & Psychiatric social workers & $6(14.6)$ \\
\hline \multirow[t]{4}{*}{ Experience of disaster mental health support } & Field experience & $28(1-10$ ry, 5 yr $)$ \\
\hline & Research & $34(1-22 \mathrm{yr}, 3 \mathrm{yr})$ \\
\hline & Education & $31(1-30 \mathrm{yr}, 5 \mathrm{yr})$ \\
\hline & Clinical experience & $31(1-20 \mathrm{yr}, 6 \mathrm{yr})$ \\
\hline \multirow[t]{2}{*}{ Perceived needs of disaster mental health support organization } & Needed & $40(97.6)$ \\
\hline & No response & $1(2.4)$ \\
\hline
\end{tabular}


Table 2. Perceived importance of each component of the K-DPATs via pairwise comparison of alternatives

\begin{tabular}{|c|c|c|}
\hline Component & Alternatives & Relative importance (\%) \\
\hline \multirow[t]{2}{*}{ Overarching structure } & Setting up a DPAT independently & 70.1 \\
\hline & $\begin{array}{l}\text { Harnessing the sporadic pre-existing resources and merging them } \\
\text { to form the K-DPAT }\end{array}$ & 29.9 \\
\hline \multirow[t]{3}{*}{ Location of headquarter* } & National-level & 59.0 \\
\hline & Regional-level & 31.9 \\
\hline & Local-level & 9.1 \\
\hline \multirow[t]{2}{*}{ Type of mobilization* } & Non-permanent organization & 44.5 \\
\hline & Permanent organizations & 55.5 \\
\hline \multirow[t]{3}{*}{ Location of expert recruitment ${ }^{\dagger}$} & National-level & 43.0 \\
\hline & Regional-level & 40.0 \\
\hline & Local-level & 16.5 \\
\hline \multirow[t]{2}{*}{ Member qualifications } & Professionals only who fulfilled particular eligibility criteria & 79.3 \\
\hline & All of valunteers & 20.7 \\
\hline \multirow[t]{2}{*}{ Certification system } & Creation of new certification & 44.1 \\
\hline & Expansion of the scope of existing certifications & 55.9 \\
\hline \multirow[t]{2}{*}{ Type of supplementary education ${ }^{\dagger}$} & Year-round & 85.0 \\
\hline & Occasional education in the case of disasters & 15.0 \\
\hline \multirow[t]{3}{*}{ Location of supplementary education } & National-level & 52.1 \\
\hline & Regional-level & 36.3 \\
\hline & Local-level & 11.6 \\
\hline \multirow[t]{2}{*}{ Remuneration system for participation } & Official payment & 82.8 \\
\hline & Volunteering without official payment & 17.2 \\
\hline \multirow[t]{2}{*}{ Funding source } & Ministry of Public Safety and Security & 65.8 \\
\hline & Ministry of Health and Welfare & 34.2 \\
\hline
\end{tabular}

*at the initial survey, the difference of relative importance between the alternatives of top- 2 components was $<10 \%$ point. The present data showed the 2 nd survey results, ${ }^{\dagger}$ according to recommendations of the expert advisory panel, this component was added in the 2 nd survey questionnaire inceptively. Repeated survey was not conducted though the difference of relative importance between the alternatives was not enough. DPAT: disaster psychiatric assistant teams, K-DPAT: Korean disaster psychiatric assistant team

using SAS 9.1 version.

The overall of surveyed items and pairwise alternatives are shown in Table 2 and Figure 1. The consistency index was used to assess the consistency of individual respondents in pairwise comparisons. In the current study, the analysis included only responses with a consistency index of $\leq 0.2$, and the consistency ratio was calculated to verify overall consistency.

The study was approved by the Institutional Review Board at the Korea National Institute for Bioethics Policy (P01201603-22-008).

\section{RESULTS}

\section{Demographic data}

Of the 41 respondents, 19 were men (46.3\%), and 22 were women (53.7\%). With regard to their fields of expertise, the proportion of psychiatrists was largest $(n=21,51.2 \%)$, followed by those of psychiatric nurses ( $\mathrm{n}=8,19.5 \%)$, clinical psychologists $(n=6,14.6 \%)$, and psychiatric social workers $(n=6$, 14.6\%). Twenty-eight respondents possessed field experienc-

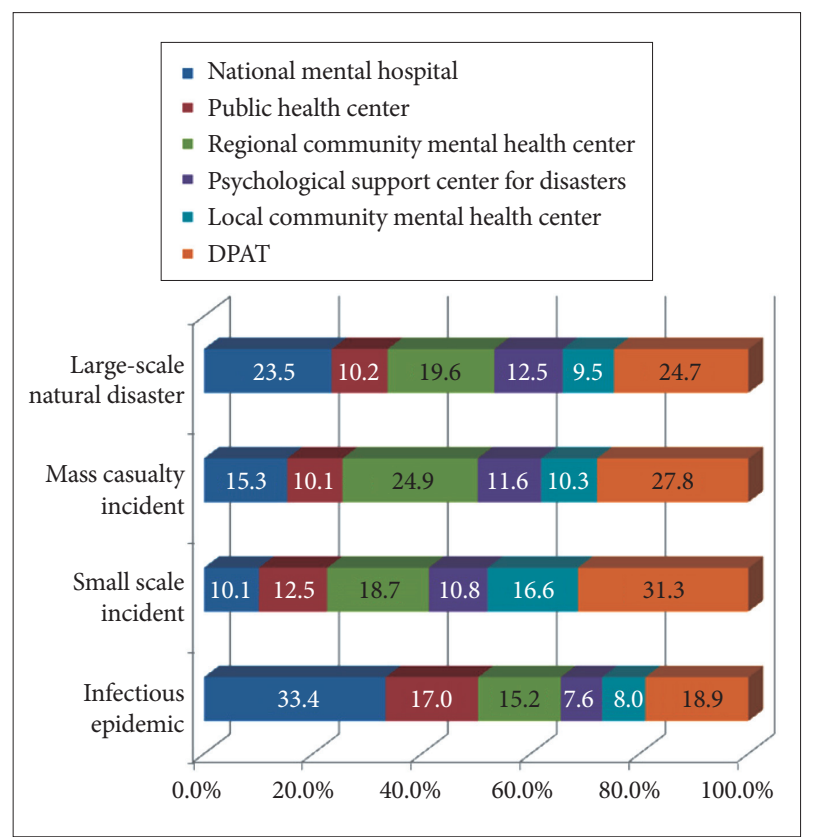

Figure 1. Perceived importance of on-site leaders of mental health services for each type of disaster. DPAT: disaster psychiatric assistant team. 
es of disaster, 34 had participated in disaster-related research, and 31 possessed disaster-related educational or clinical experience (Table 1). There was no significant difference in the general characteristics between the respondent to the two times survey both and to the first survey only in the additional analysis.

\section{Importance of the components of K-DPATs}

The authors divided the K-DPAT operation system into 10 components and examined the perceived importance of each component via pairwise comparison of alternatives (Table 2).

With regard to the overarching structure of the K-DPAT, two alternatives were considered: 1) harnessing the sporadic pre-existing resources related to postdisaster mental health services and merging them to form the K-DPAT and 2) setting up a DPAT that was independent of the pre-existing system. The importance of the latter was higher (70.1\%) relative to that of the former.

With regard to the location of the headquarters for K-DPAT management, national-level operation was perceived as most important (59.0\%), followed by regional- (31.9\%) and locallevel (9.1\%) operation. Moreover, experts perceived establishment of K-DPATs as permanent organizations (55.5\%) as more important relative to establishment as a non-permanent organization (44.5\%).

With regard to the location of expert recruitment to participate in the K-DPAT, the importance of local-level operation $(16.5 \%)$ was lower relative to that of national- $(43.0 \%)$ and regional-level (40.5\%) operation, which was similar.

With regard to member qualifications for the K-DPAT, $79.3 \%$ of respondents suggested that only professionals who fulfilled particular eligibility criteria should be granted membership. Further, experts perceived expansion of the scope of existing certifications (55.9\%) as more important relative to the creation of new certification (44.1\%). In addition, $85.0 \%$ of the experts were in favor of year-round supplementary education for all K-DPAT members.

Regarding levels of operation for the provision of supplementary education, national-level operation was perceived as most important (52.1\%), followed by regional- (36.3\%) and local-level (11.6\%) operation. With regard to the remuneration system for participation, official payment $(82.8 \%)$ was perceived to be much more important than volunteering without official payment (17.2\%). As a funding source, the Ministry of Public Safety and Security showed higher preference level of priority (65.8\%) than the Ministry of Health and Welfare (34.2\%).

\section{On-site leader according to disaster type}

The authors classified disasters into four types (i.e., large- scale natural disaster, mass-casualty incident, small-scale incident, and infectious epidemic) and examined the relative importance of the following six alternatives for on-site leaders of mental health services for each type of disaster: director of a national mental hospital, public health center director, regional mental health center director, director of the Psychological Support Center for Disasters (Korean Red Cross), director of a local mental health center, and a DPAT leader.

The prevailing opinion was that a DPAT leader should be in command during all disasters, with the exception of infectious epidemics, for which most experts suggested that a director of a national medical institution should be in command (33.4\%). During large-scale natural disasters, the perceived importance of leadership of DPAT leaders and directors of national medical institutions were similar $(23.5 \%$ and $24.7 \%$, respectively). In addition, during mass casualty incidents, the perceived importance of the leadership of DPAT leaders (27.8\%) was highest, followed closely by that of regional mental health center directors (24.9\%) (Figure 1).

\section{DISCUSSION}

The establishment of rational governance between central and local governments, administrative and professional service agencies, and public and private agencies was vital. Further, policies are required to reform the public support system, which is currently a source of confusion because it lacks integrated, coordinated intervention, particularly in the early stages of disasters. During these early stages, mental health service systems worldwide serve a similar purpose, but their structures vary. While the efficacy of treatment, continuity of social interest, and sustainability of treatment funding are important issues in the provision of mental health services in the later stages of disasters, the organization of intervention systems involves relatively greater stress during earlier stages. As a number of private services are implemented in addition to the disaster-related public service system, effective integration and coordination is essential.

The results of this study showed that securement of a pool of professionals and development of high-quality programs were important in the effective delivery of psychological support for disaster victims. The experts in the current study used the Japanese DPAT model to reach consensus regarding key issues via the AHP method. Japanese DPATs were initiated through the voluntary participation of mental health professionals during the Great Hanshin earthquake in 1995. It was later established as an official organization offering postdisaster mental health services and began to receive government funding according to the Disaster Relief Act. Japanese DPATs are established at a hospital level, and each DPAT consists of 
five or six members including a psychiatrist. DPATs operate according to the Japan Association of Psychiatric Hospitals guidelines, and some local governments, such as that of the Hyogo prefecture, have formed separate DPATs. The fact that the private sector makes a considerable contribution to Japanese DPATs has significant implications for Korean society, because as in Japan, most mental health services in Korea are in the private sector. Therefore, the national government should systematize the professional capacity of the private sector in a rational manner and integrate DPATs into operating systems for pre-existing mental health centers, to provide a public-private cooperation model established by regional and local governments. In addition, establishment of a rational service delivery system between the MPSS, which has become the control tower for disaster response since the Sewol ferry incident in 2014, and the affiliated Psychological Support Center for Disasters is also important.

The experts who participated in this study chose a system similar to the Hyogo prefecture DPAT model, rather than the general Japanese DPAT model based on psychiatric hospitals. That is, they posited that a pool of mental health professionals should be recruited and organized into regional K-DPATs, while the overall management of the teams, including the development of operation guidelines and provision of education, should be executed at a national level. As the experts agreed that K-DPAT leaders should manage on-site operations for all types of disaster, with the exception of infectious epidemics, assigning the roles of K-DPAT leaders to the directors of regional mental health centers would be conducive to efficient integration of K-DPATs into the existing system. However, in cases in which local community infrastructures are disrupted by infectious epidemics or severe earthquakes, on-site intervention should be executed at a national level, rather than regional. The participants agreed that the role of K-DPATs is to provide on-site services for mental health support first, such as Red Cross relief activities, while providing field-based professional services as a prior step in professional psychiatric treatment. In addition, they agreed that a continuing education program is required to achieve these goals. There were a few issues regarding K-DPAT composition for which clear decisions were not made in the current study. For example, consensus was not reached regarding the questions as to whether K-DPAT recruitment should be performed at a national or regional level. The prevailing opinion during the panel discussion was that the national government should establish a standing support organization to serve as headquarters, which would be responsible for education and overall operation, with K-DPATs established at a regional level. This system is somewhat similar to the existing mental health system in Korea, in which education and the operation of the

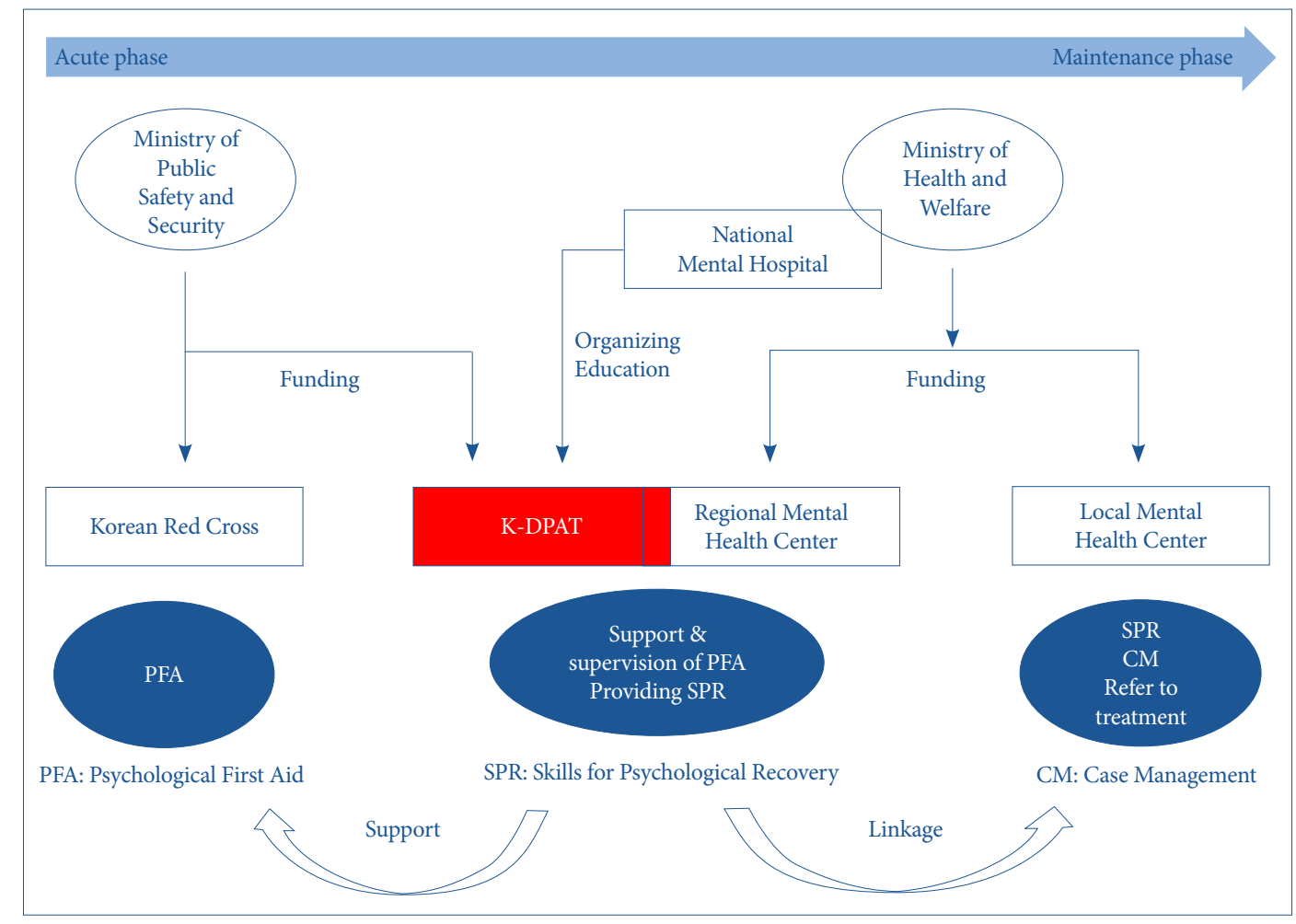

Figure 2. K-DPATs-based early-intervention model for postdisaster mental health services in Korea. K-DPATs: Korean disaster psychiatric assistant teams. 
national mental health service is performed at a national level, while services are delivered in collaboration with regional and local mental health centers. In other words, experts agreed that a professional organization, K-DTAT, should be established to serve a specific purpose while adhering to the operational features of the existing mental health service, which would reduce potential confusion.

Funding for K-DPATs is another important issue that should be managed at a national level. The experts who participated in the study reached consensus regarding a system in which the MPSS, which is responsible for disaster control, would manage funding, while the MOHW, which has a well-established network of institutions and professionals, would manage service delivery. Based on K-DPATs, Figure 2 shows an early-intervention model for postdisaster mental health services in Korea. The new model for disaster mental health response systems could improve the insufficiency of the current system, reduce fragmentation, and fulfill disaster victims' unmet need for early professional intervention.

\section{Acknowledgments}

This study was supported by a grant of the Korean Mental Health Technology R\&D Project, Ministry of Health \& Welfare, Republic of Korea (HM 15C1112)

\section{REFERENCES}

1. Bisson JI, Tavakoly B, Witteveen AB, Ajdukovic D, Jehel L, Johansen VJ, et al. TENTS guidelines: development of post-disaster psychosocial care guidelines through a Delphi process. Br J Psychiatry 2010;196:6974.

2. McConnell ES, Lekan D, Corazzini KN. Assuring the adequacy of staffing of long-term care, strengthening the caregiving workforce, and making long-term care a career destination of choice: from mission impossible to mission critical? N C Med J 2010;71:153-157.

3. O'Sullivan TL, Kuziemsky CE, Toal-Sullivan D, Corneil W. Unraveling the complexities of disaster management: a framework for critical social infrastructure to promote population health and resilience. Soc Sci Med 2013;93:238-246.

4. Inter-Agency Standing Committee Task Force on Mental H, Psychosocial Support in Emergency Settings, van Ommeren M, Wessells M. Inter-agency agreement on mental health and psychosocial support in emergency settings. Bull World Health Organ 2007;85:822.

5. Inter-Agency Standing Committee (IASC). IASC Guidelines on Mental Health and Psychosocial Support in Emergency Settings. Geneva: IASC; 2007.

6. Rodriguez JJ, Kohn R. Use of mental health services among disaster survivors. Curr Opin Psychiatry 2008;21:370-378.

7. Witteveen AB, Bisson JI, Ajdukovic D, Arnberg FK, Johannesson KB, Bolding HB, et al. Post-disaster psychosocial services across Europe: the TENTS project. Soc Sci Med 2012;75:1708-1714.

8. Suzuki Y, Kim Y. The great east Japan earthquake in 2011; toward sustainable mental health care system. Epidemiol Psychiatr Sci 2012;21: 7-11.

9. Department of Health. Planning for the Psychosocial and Mental Health Care of People Affected by Major Incidents and Disasters: Interim National Strategic Guidance. London: Department of Health; 2009.

10. Yang HH, Chen SY, Chien SY, Li WS. Forensic Investigation of Typhoon Morakot Disasters: Nausalu and Daniao Village Case Study. Taiwan: National Science and Technology Center for Disaster Reduction; 2014.

11. Panyayong B, Pengjuntr W. Mental health and psychosocial aspects of disaster preparedness in Thailand. Int Rev Psychiatry 2006;18:607-614.

12. Yamashita J, Shigemura J. The Great East Japan Earthquake, tsunami, and Fukushima Daiichi nuclear power plant accident: a triple disaster affecting the mental health of the country. Psychiatr Clin North Am 2013;36:351-370.

13. Homma M. Development of the Japanese National Disaster Medical System and Experiences during the Great East Japan Earthquake. Yonago Acta Med 2015;58:53-61.

14. Suzuki Y, Fukasawa M, Nakajima S, Narisawa T, Keiko A, Kim Y. Developing a consensus-based definition of "Kokoro-no Care" or mental health services and psychosocial support: drawing from experiences of mental health professionals who responded to the great East Japan earthquake. PLoS Curr 2015;7.

15. Kee D, Jun GT, Waterson P, Haslam R. A systemic analysis of South Korea Sewol ferry accident-Striking a balance between learning and accountability. Appl Ergon 2017;59:504-516.

16. Yang HJ, Cheong HK, Choi BY, Shin MH, Yim HW, Kim DH, et al. Community mental health status six months after the Sewol ferry disaster in Ansan, Korea. Epidemiol Health 2015;37:e2015046.

17. Lee MS, Hoe M, Hwang TY, Lee YM. Service priority and standard performance of community mental health centers in South Korea; a delphi approach. Psychiatry Investig 2009;6:59- 65.

18. Zhong S, Clark M, Hou XY, Zang Y, FitzGerald G. Progress and challenges of disaster health management in China: a scoping review. Glob Health Action 2014;7:24986.

19. Ejeta LT, Ardalan A, Paton D. Application of behavioral theories to disaster and emergency health preparedness: a systematic review. PLoS Curr 2015;7:ecurrents.dis.31a8995ced321301466db400f1357829.

20. Satty TL. Decision making with the analytic hierarchy process. Int J Services Sci 2008;1:83-98.

21. Liberatore MJ, Nydick RL. The analytic hierarchy process in medical and health care decision making: a literature review. Eur J Oper Res 2008;1: 194-207.

22. Dolan JG, Isselhardt BJ Jr, Cappuccio JD. The analytic hierarchy process in medical decision making: a tutorial. Med Decis Making 1989;9: 40-50. 